\title{
Business rescue decision-making: Post-mortem evaluation of an 'orgy'
}

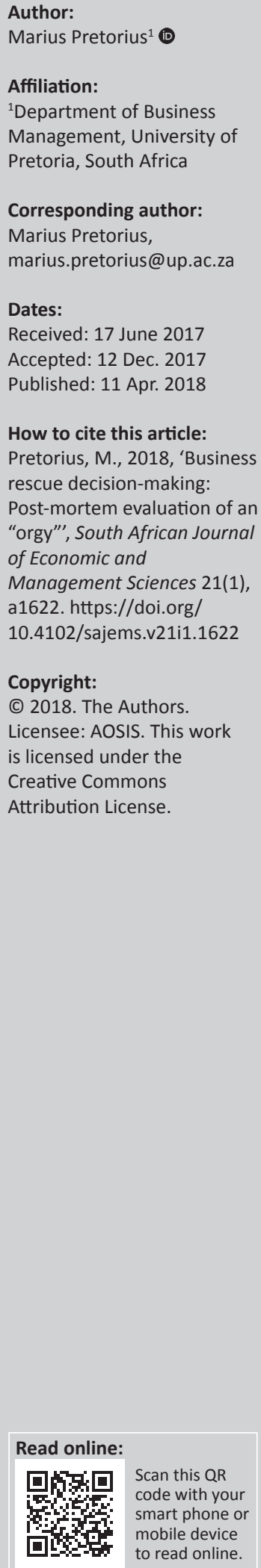

Background: Sensemaking of the extreme vagaries and external considerations that influence decision-making and judgement during business rescue events (BREs) are currently sparse but details about evaluation criteria are desperately needed.

Aim: Learning from and applying post-mortem analysis (PMA) is investigated to propose an evaluation framework.

Setting: Following the problems by and expectations of the Regulator to 'govern' the business rescue (BR) industry, a recent decision to decentralise the accreditation of business rescue practitioners (BRPs) changed the landscape significantly.

Methods: From literature and interviews, the study identified seven interactive evaluation criteria from PMA thinking to be included in a conceptual framework.

Results: Following the determination of the contextual difficulty evaluation, the measurement criteria included: taking management control, initial feasibility judgement, viability analysis, decision-making, BRP competencies, the rescue plan and compliance within the supreme task. One mediating factor, namely the BRP dominated. Secondly, the evaluation process can be costly to ensure validity of the data, collection and evaluators. Finally, BRE evaluators (executors/decision makers) require a high level understanding of contextual issues that may disproportionately influence an evaluation. Expert and master level competencies are required to inform the proper judgement of the evaluation criteria and variables.

Conclusion: The study addresses educators' need for a framework for PMA to guide the teaching of BRP competencies, direct the regulatory authorities (and professional bodies) accreditation framework for licensing BRPs, inform banks as creditors to enhance their information systems, advise upcoming BRPs on outcomes while courts may consider the framework as useful for judging issues.

\section{Introduction}

Paradox in business rescue is endemic. No better understanding is required than King's (1975) quotation of Arnold's (1943) statement about the feasibility of corporate reorganisation when he postulated:

The ritual of corporate reorganization ... is perhaps the most interesting of all our legal rituals from a ceremonial point of view, because it is the most complicated mystery of all. ... [It] is a combination of a municipal election, a historical pageant, an antivice crusade, a graduate-school seminar, a judicial proceeding, and a series of horse trades, all rolled into one - thoroughly buttered with learning and frosted with distinguished names. Here the union of law and economics is celebrated by one of the wildest ideological orgies in intellectual history. Men work all night preparing endless documents in answer to other endless documents, which other men read in order to make solemn arguments. At the same time practical politicians utilize every resource of patronage, demagoguery, arid coercion beneath the solemn smoke screen. Although to the casual observer the complications seem most forbidding, actually the dialectic of this process is very simple. It consists in the endless repetition in different forms of the notion that men must pay their debts, in a situation in which neither men nor debts in any real sense are involved. (p. 304)

From this insight using the orgy as metaphor, one can derive several obvious paradoxes, namely the 'complicated mystery' of an orgy versus the 'very simple process' it uses, the rituals that exist for a long time and are probably followed without sufficient questioning versus the uncertainty (smoke screen) and crisis events where law and economics intersect and, finally, the role focuses on those involved. Indeed, paradox is the rule, not the exception to make sense of by decisionmakers in a business rescue event (BRE). The views that are taken within these BRE circumstances depend on who the observer is, suggesting that such an 'orgy' may be perceived as simple, 
complicated, complex or even chaotic (Kurtz \& Snowden 2003) and influenced by its unique specifics.

Turnarounds, rescues and the involved professionals are judged continuously, especially when affected parties to a BRE feel aggrieved. When one must make sense of a business rescue (BR) and potentially judge the success thereof, there is little replacement for experience and a contributor to the sensemaking process. Chapter 6 of the 2008 South African Companies Act provides for the business rescue practitioner (BRP) to file substantial implementation as a 'measure' to judge successful execution of the rescue plan - unfortunately, substantial implementation is ill defined as to what exactly such a measure consists of. BR Portal (2013) reported the reputation of business rescue as clouded in vagueness and the role of the BRPs as a critical scenario driver for the rescue industry.

Evaluating the outcome of a rescue for a distressed venture (firm or organisation) has become an immensely important process because of the potential consequences that the reappointment of a BRP may have for future creditors, shareholders and affected persons considering BR. Baird and Lorence (2012:21) postulate that within the turnaround industry there are currently no broadly accepted tools, systems or processes to predict the success of turnarounds. Similarly, for the evaluation of BRE, the questions that arise are: 'What evaluation criteria should be included when executing a post-mortem (PM) evaluation of a BRE that can guide the regulator and professional bodies concerning the accreditation of the BRP profession?' and 'What are the variables that would constitute each indicator to support the evaluation process?' The intertwined nature of these questions calls for a framework to enhance business rescue evaluation in line with Trahms, Ndofor and Sirmon's (2013) call for further research in this field.

At present, there remains inadequate regulation (Bradstreet 2010) and the proposed selection guidelines for BRPs remain a bone of contention for the regulator, as well as directors of distressed businesses who want to appoint them. It appears that the number of removal and replacement attempts (Section 139) support that all is not well for the 'success' perspective in the industry. At the same time, BRPs are reported as both successful in some of their cases (reported by themselves and their website claims) while simultaneously complaints circulate about their 'colossal' failures in others as reported by creditors, directors who appointed them as well as court judgements. On enquiry, BRPs then easily blame some or other technical aspect for the 'failed BRE'. Such excuses range from non-existence of reasonable prospect from the start to abuse of the business rescue process by directors to absence of willing post-commencement finance (PCF) providers and several other reasons. Within the industry and Chapter 6 of the Act, there is no meaningful evaluation system for business rescues, which is the problem that this article addresses.

Anticipating the role of evaluation on their reputations, the 'better' practitioners have begun recording the number of 'refusals when asked to act as a BRP for a specific rescue', as well as the number of times they are approached to 'replace an already appointed $\mathrm{BRP}^{\prime}$ in an existing BRE. Removals are court processes mostly driven by creditors who are unhappy with the appointed BRP. These refusal figures are used by BRPs to promote their number of successes and market their services. Despite the trustworthiness of such numbers being questionable, they support the lack of measures to describe the success of BR. Pretorius (2015) reported the success rate as $9.4 \%$ in a report on the industry after 3.5 years (Inception May 2011) of implementation of Chapter 6 . He warns, however, that the figure must be contextualised, while he believes that it might be closer to $5 \%$ partly because of the twin definitions of the purpose of BR as described in Section 129(3).

Business rescue practitioners (including turnaround managers) face complex assignments with unclear measurements in practice. Each rescue has unique circumstances which make these judgements subject to the perception of 'whoever is asked', be it the BRP, creditor, directors, legal advisor or other affected persons (Elliot, pers. comm., 2015). Also, no formal scientific research to support the descriptors by the Act for this 'new phenomenon' exists to guide the Companies and Intellectual Property Commission (CIPC), the appointed regulator.

While there is a need to advise distressed businesses that want to file for rescue, as well as future applicants who want to be certified, on the competence requirements for certification of BRPs, two obvious stakeholders are foremost in driving the need for an evaluation framework. Firstly, educators would welcome evaluation methods, as currently these are unclear. Teaching of standard business management measurements is insufficient, as businesses in distress face more complex circumstances, which Midanek (2002:24) refers to as having 'war zone' circumstances. Yet the particular processes to apply remain elusive. Secondly, the professional bodies whose members embark on the BRP profession urgently require monitoring frameworks to govern their processes. Finally, banks as the largest creditors can benefit from the feedback to reduce their future risks.

This article builds on four key activities describing the tasks for BRPs (Section 141) to execute during rescue, and takes cognisance of a fifth 'supreme task' identified by Pretorius (2013) and the associated competencies required (Pretorius 2014) for navigating a business rescue by a BRP. The paper then expands and builds on the directives of Conradie and Lamprecht (2015) for the measurement of rescue success to establish an evaluation framework and propose the considerations for a BRE evaluation through PM analysis.

This article briefly summarises the relevant aspects of Chapter 6 of the Act and its prescriptions and requirements as boundary conditions. Secondly, it reports briefly on the relevant key principles of PM analysis (or review) and critical incident technique (CIT) with their specific contributions as cornerstones of the research, namely finding the main measurement criteria 
of success and substantial implementation. It then presents the methodology of this research to use existing theory in guiding practical application. Fourthly, it reports the findings and, finally, proposes a conceptual evaluation framework. The proposed framework describes the evaluation criteria and contextual considerations underlying the evaluation framework to be executed after a BRE. The resulting framework could be used to direct the industry and to trigger debate about both rescue and BRP competence measurement, based on its findings.

\section{Research question}

At this point, the regulator has no distinct guidelines other than the vague disqualifications from the Act (Section 138) for BRP appointments and none for the evaluation of substantial implementation and success of a BRE. At the same time, the Act suffers from vagueness and courts depend on previous and earlier judgements to establish direction. This aspect is important, as the rescue industry is just about 7 years old, following the legislation since Chapter 6 of Act 71 of 2008, as amended, which came into effect on 1 May 2011. The CIPC, as regulator of the rescue industry, has recently decided to abolish the ad hoc licensing approach in favour of pre-screening with professional bodies that take responsibility (vetting) for their member qualifications and accreditation framework. A proposed evaluation framework is the design outcome of this article.

\section{The research question is thus:}

What are the evaluation criteria (and their associated variables) to be considered during post-mortem analysis of a business rescue event?

The research objectives are to design and propose a conceptual evaluation framework, firstly by drawing from literature and informing it by inteviews. Secondly, the potential criteria and their variables are expounded. After that, weight allocation is addressed to inform the framework. Finally, the proposed variables are then rated to demonstrate the working of the framework. Answering these questions then allows for proposing an analysis and evaluation framework to guide decision-making when executing such a post-mortem evaluation of a BRE.

\section{Background to rescue and rescue practitioners}

As this article aims to add and apply theory, this section briefly summarises the context of business rescue for the reader and expounds substantial implementation based on post-mortem analysis (PMA) and how the research gives direction to constructing an evaluation framework for evaluation BREs.

\section{Summarised essential process of business rescue and its evaluation in South Africa}

Without fully expanding on the technical aspects of BR in detail, this section highlights the process and issues of BR relevant to this article in a narrative form.
A BRP is appointed through a voluntary or court process to rescue a distressed firm. After basic investigation, the BRP obtains support (or informs) at the first creditors' meeting that he will pursue the rescue based on his reasonable prospect perception and judgement. The BRP can do so for either reorganisation or better return than an immediate liquidation (BRiL) as objectives prescribed in the Act. He then compiles a rescue plan on which the creditors must vote at the second creditors' meeting. If supported, especially by PCF providers, the BRP must then implement the plan until substantial implementation (Section 152(8)) has been achieved or, alternatively, terminate the rescue (Section 141(2)bii).

Often various and unplanned 'incidents' may happen during the process, which may alter the conditions or derail the planned rescue. Rescues may then result in incapacitating court battles, failed rescues for multiple reasons and often eventual liquidation after amassing significant costs to company and losses to the creditors. Affected parties then, in retrospect, blame various aspects that the BRP did not 'execute correctly', depending on the 'stakes' they held in the firm that determined their perceptions. During the process, information asymmetry and data integrity underscores the variety (often opposing) of the perceptions. Elliot (2015) suggests that the success of a recue depends wholly on 'who you ask', confirming the non-factual nature of 'success' in BR.

The number of variables in a distressed venture associated with the turnaround situation or event are many. These may even multiply during the rescue, making it difficult to 'pinpoint' a single measure when the BRE is evaluated. There are multiple stages at which such BRE judgements are required, however, substantial implementation or termination of the rescue being the most important infliction points. This then requires retrospective judgement. PMA, well used in project evaluation, lends itself to this type of evaluation. Next, the principles of PMA and CIT are explored to determine their relevance and usefulness to the BRE evaluation.

\section{Changes in licensing requirements from the Act for business rescue practitioner appointment}

From the onset, BRP licensing has rested on Section 138(1), prescribing requirements such as:

- Member in good standing of a legal, accounting or business management profession.

- Not subject to an order of probation.

- Would not be disqualified from acting as a director of the company.

- Does not have any other relationship with the company.

No mention was made of the specific knowledge, skills, ability or competency requirements except for those implied in the licensing requirements. These are left to the interpretation of the regulator.

Until recently, these BRP licenses were conditionally awarded for a specific rescue project after being nominated by the 
relevant distressed company. Licenses were allocated on the basis of relevant experience and appropriate references (track record), together with some exclusion provisos to the granting of the once-off license. No prescribed system or set of absolute prerequisites were established for licensing practitioners.

The regulator has, to date, reported several problems that gave rise to the alternative licensing system now pursued. Evaluation of BRP track records has now become highly relevant. Following these problems by and expectations of the regulator to 'govern' the business rescue industry, a recent decision to let professional bodies take responsibility for the accreditation of their members as BRPs changed the landscape significantly. Simultaneous to this process, the Minister of Trade and Industry has informed the regulator that the 'implementation and monitoring the effectiveness of business rescue' has been identified as a key policy from 2016/2017 onwards by his office (Davies 2016). This study, therefore, aims partly to provide directives for a BRE analysis framework, firstly to guide future licensing through better understanding of the exact measurements required for the work that BRPs perform and, secondly, to address accreditation requirements and guidelines as a part of monitoring business rescue.

Evaluation guidelines by the Act are vague. Competency requirements are guided by understanding why BRPs may be disqualified, namely in cases of incompetence or failure to perform the duties of a business rescue practitioner of the particular company. Section 139(2) describes incompetence as the 'failure to exercise the proper degree of care in the performance of the practitioner's functions; engaging in illegal acts or conduct; if the practitioner no longer satisfies the requirements.' Other guidelines which are difficult to measure are set out in Section 138(1) under the disqualifying variables of:

... conflict of interest or lack of independence ... or if the practitioner is incapacitated and unable to perform the functions of that office, and is unlikely to regain that capacity within a reasonable time.

Here, BRP competency is implied through delineating incompetency conditions but without specific details about the competency required. No associated guidelines exist for substantial implementation of a rescue plan.

\section{Tasks and competencies of business rescue practitioners}

Section 141 of the Act prescribes what BRPs must do on taking control of the business, investigating the affairs thereof, compiling a rescue plan and implementing it if approved. Pretorius (2013) claims a fifth task namely the 'supreme task' to comply with the legal process requirements. He thereafter describes the competencies that BRPs require to include analysing, sensemaking and integration through collaboration competencies (Pretorius 2014) in order to navigate a business rescue. Several court judgements now support the importance of these competency requirements as evidence. Many allegations exist in the industry about the absence of these skills.

\section{Success in business rescue}

Conradie and Lamprecht (2015) ventured into the evaluation of success in business rescue. They compared evaluation criteria used in four international bankruptcy regimes (USA, Canada, Australia and UK) that can serve as key indicators towards BR evaluation. They further suggested the consideration of short-term and longer-term success evaluations. To be considered as successful, their identified goals included that the company must emerge as a going concern and remain economically viable; if not, BRiL should be achieved and finally protection of all stakeholders should be achieved. For these goals, they reported 10 evaluation criteria (based on international regimes), namely five business-related goals (number of entities saved, return to economic viability, comparative return, approved BR plan and key operations remaining) and five that are financial ratio comparisons (restored liquidity, restructured debt, restored profitability, change in asset size and comparative share portfolios). Given the status of data integrity and information asymmetry reported in the BR industry, it is doubtful whether these evaluation criteria are at all useful for any other than public companies registered on the stock exchange. Their study reiterated the absence of clear, objective and applicable measures for generic determination of a business rescue success and they call for the 'development of a scorecard or matrix to give proper weight to the different criteria' (p. 25).

Research on the status of the BR industry (Pretorius 2015) commissioned by the regulator after the first 3.5 years of the regime, reported a $9.4 \%$ success rate. At the same time, it reports a general misunderstanding of what success means in BR. The fact that pursuing a BRiL is also considered as success often clouds the perceptions (Pretorius 2015:5) of what normally is associated with a reorganisation of a distressed business. What the report does expound is the complexity of the variables that are associated with success, namely the creditor's vote and its dependence on the rescue plan, the role of the BRP within the process, the impact of the reasonable prospect judgement for creditor support and new investment (PCF) and, finally, the need for general education for BRPs, affected persons and the public alike.

\section{Why post-mortem as a technique}

The value of PM processes will not be argued; rather its principles and reasons for use will be investigated. Fischhoff (1980) already postulated that we do retrospective analysis to answer three basic questions: firstly, are there patterns upon which we can capitalise so as to make ourselves wiser in the future? Secondly, are there instances of folly in which we can identify mistakes to avoid? And, finally, are we really condemned to repeat the past if we do not study it? That is, do we really learn anything by looking backwards? 
To evaluate a BRE meaningfully, retrospective analysis after implementation of the BR plan is proposed for use in this study. Also, when termination of a BR is filed after a long attempted rescue, the PM analysis becomes crucial to establish improved sensemaking of possible wrongdoing. Within the project management body of knowledge, the concept of PM analysis has been well established for many years. PMA has several variants suggesting minor alterations during application to adjust to different contexts (Myllyaho et al. 2004). PMA is also known as PM review. The benefits of PMA relevant for BREs are reported to include: it helps project teams to better understand different perspectives; it identifies hidden problems; it documents good practices and problems. PMA takes aim at those areas with maximum potential for improvement (Collier, DeMarco \& Feary 1996:66), thus purporting a positive slant on the retrospective view of an event. Underlying it all appears to be the goal of learning based on the event because the consequences only become clear afterwards.

Edvardsson and Roos (2001) critically evaluated related techniques associated with PMA referred to as critical incident technique (CIT). The principles of both also have value although it has not been applied in business rescue, which is one discrete incident containing many subprocesses and elements. What is relevant for BR is that applying CIT allows for the making of judgements by subjects about the patterns and consequences of a particular incident. Underlying all the techniques is the principle of retrospective judgement based on the experiences of the subjects interviewed. This appears to have great value for business rescue and the proposed framework for sensemaking.

Bjornson, Wang and Arisholm (2008) add a more in-depth PMA technique to understand the root cause of project problems. While the root cause is not the aim of PMA in general, for this article it is important to understand the connection to more in-depth analysis that may follow the standard PMA.

Based on the above techniques, this study responds to the need for research to conceptualise the measurement criteria required during the process of evaluating a business rescue and, simultaneously, to point out the key concepts associated with the required evaluation criteria. This research proposes a conceptual organising framework for the PMA of a BRE.

\section{Methodology}

The research aims to propose a BRE PMA framework leaning firstly on the PM literature and, secondly, on the measurement criteria obtained from BRPs who must evaluate their peers during PMA. Finally the method was applied to two random rescues to seek credibility and observe its potential practical limitations. It therefore involves description, understanding but mainly sensemaking and interpretation supplied by the subjects.

\section{Research design}

Table 1 summarises the research design and is followed by a detailed description of the design elements.

In attempting to answer the research question, the researcher was aware of his own beliefs, experiences, philosophical assumptions and methodological values. These assumptions could influence how the research was conducted and are stated in order to understand the 'intellectual climate' in which the research was conducted. The theory of knowledge (epistemology) of the researcher describes how one can discover underlying principles about social phenomena and how one can demonstrate knowledge. The researcher's personal experience with business failure ignited his interest in business rescue. At the same time, as an academic and experienced turnaround consultant, he has a preference for factual directives. To mitigate these potential biases and subjectivity, a structured data-gathering method through interviews was used to capture the activities and experiences of the subjects during their evaluations. Thus, the research was interpretative and thus the researcher's sensitivity towards his potential positivist biases.

An ontological position comprises the researcher's view on the very nature and essence of the research reality. The researcher, as an objective practicalist, believes that knowledge comes from facts associated with real-life cases and their context. If the researcher found repeated mentions of practices and praxis, he could generalise from them. At the same time he acknowledges the importance of the subjects and their views based on their practical experiences. His interest was mainly to identify directives to establish a tool to assist accreditation.

TABLE 1: Research design of this study.

\begin{tabular}{|c|c|}
\hline Component & Description \\
\hline Research problem & $\begin{array}{l}\text { Lack of a framework to evaluate BREs for substantial } \\
\text { implementation and 'success'. }\end{array}$ \\
\hline Research aim & $\begin{array}{l}\text { To propose a framework to guide regulators and } \\
\text { professional bodies in accreditation of BRPs and } \\
\text { creditors to ensure professional compliance. }\end{array}$ \\
\hline Research question & $\begin{array}{l}\text { What are the evaluation criteria (and their associated } \\
\text { variables) to be considered during post-mortem } \\
\text { analysis of BREs? }\end{array}$ \\
\hline Context & $\begin{array}{l}\text { Business rescue legislation effective since May } 2011 \\
\text { and following the 'deregulation' of BRP accreditation. }\end{array}$ \\
\hline Phenomenon investigated & $\begin{array}{l}\text { Evaluation criteria (Indicators) and their variables to be } \\
\text { considered to execute a post-mortem evaluation of a } \\
\text { BRE. }\end{array}$ \\
\hline Unit of observation & $\begin{array}{l}\text { BRP opinions on BR success and peer evaluation of } \\
\text { BREs and peers. }\end{array}$ \\
\hline Method & $\begin{array}{l}\text { Data collected through unstructured interviews with } \\
\text { BRPs who were requested to advise the researcher on } \\
\text { how 'rescue and peer evaluations' should be } \\
\text { conducted during a post-mortem analysis of a BRE. } \\
\text { Based on their responses they were challenged from a } \\
\text { devil's advocate perspective. }\end{array}$ \\
\hline $\begin{array}{l}\text { Logic linking the data to the } \\
\text { propositions }\end{array}$ & $\begin{array}{l}\text { Instructions and comments by BRPs about the } \\
\text { potential measurements to apply in the post-mortem } \\
\text { analysis of a BRE contain key insights into the } \\
\text { evaluation criteria with their variables to be included } \\
\text { in the PMA framework. }\end{array}$ \\
\hline $\begin{array}{l}\text { Criteria for interpreting the } \\
\text { findings }\end{array}$ & $\begin{array}{l}\text { Insights and understanding of the researcher proposed } \\
\text { in a BRE PMA evaluation framework. } \\
\text { Practical applicability of the proposed framework to } \\
\text { test applicability of the process and frameworks. }\end{array}$ \\
\hline
\end{tabular}

Source: Based on Yin, R.K., 2003, Case study research: Design and methods: Applied social research methods, 3rd edn., Series vol. 5, Sage, London

$B R$, business rescue; BREs, business rescue events; BRP, business rescue practitioner; PMA, postmortem analysis. 


\section{The interview setting, process and sample}

As the researcher knows many rescue practitioners and often interacts with them, both individually and collectively, access to subjects was easily achieved. He perceived every interaction with BRPs as a research opportunity as it allows informal personal narratives to appear. The nature of the context lent itself to unstructured interviews. BRPs were asked two main questions whereupon informal probing took place. This turned into a 'dialectic conversation' as the subjects were challenged as if by a 'devil's advocate'. The primary 'trigger' questions were:

- How should one evaluate a rescue to judge its success or not?

- Subjects would give pointers leading to a dialectic conversation and thereafter were challenged on their statements.

- How should one go about a peer evaluation of a BRP?

- Inadvertently, specific 'other' BRPs were named while subjects explained their 'wrongdoings' - many insights were gained through this question. Unfortunately, this depended entirely on the extreme level of trust between researcher and subject and no recording of the interviews was agreed upon.

For the subjects it was an opportunity to reflect on and progressively enrich their own thinking about the evaluation of their own work. The process of data collection thus constituted an opportunity for the subjects to expand their possibility of acting in the world, not only to draw on their experiences but also to draw on their creativity.

A purposive sampling strategy was used. BRPs who had been licensed as senior BRPs several times before were selected for participation. The sample was limited to senior BRPs as it is believed that they could contribute most based on their 10-year minimum experience requirement. Saturation was observed after eight interviews. However the interviews were continued (and are still ongoing) beyond 12 as there was always the possibility of discovering unique variables. Finally there were 16 interviews considered.

\section{Data collection procedures}

Firstly, the literature on PMA and CIT relating to evaluation prescriptions was studied to guide indicator development for the BRE evaluation. Secondly, an interview process was applied to senior BRPs during personal interactions with the researcher to collect primary data. The ultimate output of the full study was to create a practical evaluation framework based on subject feedback but interpreted by the researcher.

The approach was one associated with an evaluation format completed by the researcher. The boundaries between the subjects and their rescues were not clear, as they had had direct involvement with their own experiences (rescues performed). This meant that the researcher could pursue different angles of evidence to seek convergence and divergence. In addition, because their experiences were recent, there was sufficient access to short-term memory and associated learning from their practical experience. Being a small industry, all were knowledgeable about the facts and aware of the rumours circulating about one another.

Subjects participated voluntarily. It was found that they were relaxed during interviews as there was a trust relationship, as shown by their open responses and even bantering about rescue. It is believed that these positive conditions led to biased (wanted) sharing and meaningful contributions drawn from the prompting.

\section{Strategies for ensuring quality data and interpretation}

While there was only one source of evidence (BRPs), the researcher also sought confirmation by 'sensemaking discussion' with peer academics (legal, financial and business), as well as bank representatives. These discussions assisted firstly in 'outsider checking' as well as identifying leads and probes to use during interviews. As the focus was exploratory (asking 'what') and explanatory (asking 'how'), the process elicited the perceptions of the subjects, thus improving internal validity (Yin 2003:34). BRPs wrote their own responses.

As there was only one researcher, he depended on several readings of the notes taken. On the basis of his experience in rescue and his extensive preparation, variables and evaluation criteria were identified iteratively and eventually meaningful indicator categories could be constructed. Once categories were obtained, each was populated in an iterative process with variables to balance the number of variables per indicator, with the aim of developing a balanced instrument (questionnaire). This led to the developed evaluation criteria being challenged and occasionally reallocation of variables took place during iterations, until balance was achieved.

Finally, when a variable could support more than one evaluation criterion, the researcher allocated it to the appropriately judged category, based on the most 'useful' association with the criterion.

\section{Data analysis}

Although there was only one key source of evidence (the subjects' contributions), the researcher used grounded theory principles to develop themes that became the eventual evaluation criteria (Corbin \& Strauss 1990; Henning 2011:138). To extract as much richness as possible, the framework depended on the researcher's sensemaking when interpreting the subject contributions. Notes on the researcher's insights gained during the interviews were the main source of data.

The research style was exploratory, to identify and describe the evaluation criteria for measurement (directed by firstorder variables) and how they can be applied in the execution process of the evaluation. Eventually, after understanding how variables related to the BRE evaluation process, the subjects proposed sources of data, as well as verification of 
the information from the rescue plan. On the basis of the overall insights gained, the researcher conceptualised and proposed a PMA framework for discussion.

\section{Findings}

Firstly, BRE evaluation requires decisions starting with an assessment about the complexity of the specific rescue context as all rescues differ in several aspects (see Table 2), namely: (1) the nature of the turnaround situation faced, such as underperformance, strategic distress, distress while performing well or crisis as described by Pretorius (2008). Secondly, (2) the severity associated with the decline of the specific BRE with its associated difficulty to turn around should be considered. This is influenced by (3) multiplicity which describes the complexity of the organisational structures as far as divisions, branches, industry types and product ranges are concerned. If (4) extraordinary events (once-off) such as key customer failure, contract withdrawals or deliberate legal action against the firm triggered the BRE, they may complicate difficulty and severity. Under conditions where (5) shareholder disagreement exists or where they are blamed for 'abuse' or suspect objectives, complexity increases. This is often associated with (6) lack of data integrity (Pretorius \& Hotzhauzen 2008) which may be a deliberate ploy by filing management. When a BRP is forced to use forensic audit processes to trace funds and confirm transactions, it increases complexity. Finally, there are (7) extenuating factors such as tax structuring associated with fraud that may add to the overall complexity judgement for a BRE.

It is contextually critical that evaluators must be clear that individual BREs vary significantly and variables may (or may not) feature at various levels depending on the specific context of the BRE. Thus, based on the above, there may be overlaps between some variables visible, for example where severity and the nature of the turnaround situation are associated variables. This is addressed by weight allocations and expanded in the discussion. The weightings shown in Table 2 therefore vary for each BRE subject as to their appropriateness. In-depth knowledge of the specific BRE is therefore paramount and may eliminate the novice evaluator. Similar to decision-making models used in strategy evaluations, the weighting in a specific category should add up to total of 1.0 allowing the evaluator some freedom in prioritising the variables. This is also expanded after the criteria are explained.

While reporting the rest of the findings, quotation marks are used to show direct responses from the subjects. It seemed that the variables of this study showed similarity in nature to those identified as indicators by Conradie and Lamprecht (2015:20).

The findings further pointed towards seven evaluation criteria each with variables of relevance to the evaluation of a BRE. Table 3 is presented at this early juncture to visually enhance the categorisations and report the variables within each indicator that can contribute to the evaluation. It also shows potential weight contributions of variables to be considered and suggests the potential sources of the data and the metric that might be useful for each variable. For example, one subject stated that 'if you suspect abuse, you focus more on financial control than management control'; therefore, the weightings for that specific BRE will change from one event to the next. This weight allocation is therefore a key principle in the proposed process.

The variables associated with each criterion are discussed individually later in the article. Each evaluation criterion is now explored briefly in search of the relationships with variable factors within. Evaluation criteria are reported in operational sequence rather than apparent importance or contribution. Following the proposed evaluation criteria is a discussion of variables relevant to the categories in Table 3. Table 3 is presented at this early juncture to guide the discussion of the evaluation criteria. Table 3 further shows a rating for each variable resulting in the data point within Figure 1.

\section{Evaluation criterion 1 - Taking control and execution of the business rescue event by the business rescue practitioner}

Taking management control of the BRE by the BRP appears to be of the utmost importance and relates to the first task

TABLE 2: Evaluating the complexity of the rescue context for the specific event under investigation, where variables were rated on a 5-point Likert scale (with $1=$ Very easy and $5=$ Very tough or difficult).

\begin{tabular}{|c|c|c|c|c|c|}
\hline Variable & Weight $\uparrow$ & Interview judgements & Potential sources & Potential evidence (Metrics) & Rating \\
\hline Turnaround situation nature & 0.2 & Category description & Rescue plan & $\begin{array}{l}\text { Under performance, strategic distress, } \\
\text { crisis, performing well }\end{array}$ & 3 \\
\hline Difficulty, severity & 0.2 & Time and depth of whole, severity & Rescue plan & $\begin{array}{l}\text { Solve by financial, business or debt } \\
\text { restructuring }\end{array}$ & 2 \\
\hline Multiplicity & 0.1 & Divisional complexity, capacities & Act & $\begin{array}{l}\text { Ownership, divisions, branches, locations, } \\
\text { variations in portfolio }\end{array}$ & 1 \\
\hline Extraordinary events & 0.1 & Legal opposition & Rescue plan & $\begin{array}{l}\text { Contract withdrawals, caveats, } \\
\text { non-payments }\end{array}$ & 1 \\
\hline $\begin{array}{l}\text { Shareholder conflict or } \\
\text { agendas }\end{array}$ & 0.1 & $\begin{array}{l}\text { Disputes and disagreement } \\
\text { investigations }\end{array}$ & Shareholders & Board minutes & 1 \\
\hline Data integrity threat & 0.2 & $\begin{array}{l}\text { Clarity change from filing to second } \\
\text { creditors' meeting }\end{array}$ & Act & Audits required, forensics & 1 \\
\hline Extenuators & 0.1 & $\begin{array}{l}\text { Extenuating circumstances, tax } \\
\text { structuring }\end{array}$ & $\begin{array}{l}\text { Act, shareholders, } \\
\text { employees, lawyers }\end{array}$ & Fraud, other & 1 \\
\hline
\end{tabular}

$\dagger$, Weights are allocated based on the relevance for the specific rescue under investigation. Some variables are more influential depending on the specific context. 
TABLE 3: Evaluation criteria and variables in the proposed evaluation framework for business rescue events.

\begin{tabular}{|c|c|c|c|c|c|}
\hline Variable & Weight $\dagger$ & Interview judgements & Potential sources & Potential evidence (Metrics) & Rating: \\
\hline \multicolumn{6}{|c|}{ Evaluation criterion 1 - Taking management control and execution by BRP } \\
\hline Taking management control & 0.15 & Steps taken & Bank & Minutes, alternative structures & 4 \\
\hline Taking financial control & 0.15 & Bank signing powers & Shareholders, bank, creditors & $\begin{array}{l}\text { Support plan, coaching, } \\
\text { communication strategy }\end{array}$ & 3 \\
\hline Employee control and support & 0.05 & Meetings & Employees & Labour Act compliance & 1 \\
\hline Role clarification & 0.1 & Judgement & Act & Delegations sheet, process used & 3 \\
\hline Implementation steps & 0 & Judgement & Rescue plan & Scorecard & 4 \\
\hline Meet with and communicate & 0.4 & Judgement on feedback & & Meeting schedules & 2 \\
\hline Control of change process & 0.15 & & Shareholders, Act & Creditor and employee feedback & 3 \\
\hline \multicolumn{6}{|c|}{ Evaluation criterion 2 - Feasibility analysis: Business affairs } \\
\hline Feasibility analysis and basis & 0.3 & $\begin{array}{l}\text { Demand, capacity, business } \\
\text { model, cash flow, caveats }\end{array}$ & $\begin{array}{l}\text { Rescue plan, shareholders, } \\
\text { employees }\end{array}$ & & 3 \\
\hline $\begin{array}{l}\text { Accuracy of the turnaround } \\
\text { situation (TAS) identification }\end{array}$ & 0.2 & $\begin{array}{l}\text { Description, motivation, } \\
\text { statement }\end{array}$ & Rescue plan, shareholders & TAS matrix & 4 \\
\hline Causality of distress & 0.2 & Clarity of identification & Rescue plan & & 2 \\
\hline Response to contextual difficulty & 0.1 & $\begin{array}{l}\text { Description of causality } \\
\text { response match }\end{array}$ & Rescue plan & Alternatives, scenarios offered & 4 \\
\hline Basic business analysis used & 0 & & Rescue plan & & 2 \\
\hline Constraints/caveat identification & 0.1 & & Rescue plan, shareholders & Maps, explanations & 4 \\
\hline \multicolumn{6}{|c|}{ Evaluation criterion 3 - Viability analysis (Financial affairs) } \\
\hline $\begin{array}{l}\text { Overcoming liability of data } \\
\text { integrity }\end{array}$ & 0.3 & $\begin{array}{l}\text { Verification steps, system, } \\
\text { process }\end{array}$ & BRP & Direct question & 2 \\
\hline Liquidation benchmarks & 0.1 & & Rescue plan & $\begin{array}{l}\text { Verification, statement, better or } \\
\text { not, assumptions }\end{array}$ & 2 \\
\hline Cash status description & 0.2 & & Bank & $\begin{array}{l}\text { Practices, budget, projection, BRP } \\
\text { pay }\end{array}$ & 2 \\
\hline Balance sheet analysis & 0.1 & & Bank & Practices, report, bank signing & 2 \\
\hline Pre-filing investigation & 0.15 & Investigation & Act & $\begin{array}{l}\text { Reference to financial } \\
\text { statements, Board of Directors } \\
\text { minutes, contracts }\end{array}$ & 2 \\
\hline Bank management and role & 0.15 & Bank support statement & Rescue plan & $\begin{array}{l}\text { Meetings, new accounts, bank } \\
\text { support statement }\end{array}$ & 2 \\
\hline \multicolumn{6}{|c|}{ Evaluation criterion 4 - Business decision-making } \\
\hline $\begin{array}{l}\text { To pursue business rescue - First } \\
\text { creditors' meeting }\end{array}$ & 0.3 & $\begin{array}{l}\text { Triage, description, } \\
\text { shade of grey }\end{array}$ & Rescue plan & $\begin{array}{l}\text { Minutes of first creditors' } \\
\text { meeting }\end{array}$ & 4 \\
\hline $\begin{array}{l}\text { Control of Human Resources - } \\
\text { Retrenchment }\end{array}$ & 0.2 & & Rescue plan & Cost containments, staff & 4 \\
\hline Control of operations & 0.05 & Continuity operation & Rescue plan & & 3 \\
\hline $\begin{array}{l}\text { Choice of Section } 128(b) 1 \text { or } 3 \\
\text { (BRiL) }\end{array}$ & 0.05 & Judgement & Rescue plan & Motivation & 3 \\
\hline Market demand protection & 0.15 & $\begin{array}{l}\text { Mention in plan, announcement } \\
\text { at first creditors meeting }\end{array}$ & Rescue plan & $\begin{array}{l}\text { Structure, formality, management } \\
\text { meetings, press activity }\end{array}$ & 3 \\
\hline Handling 5 to 12 responses & 0.1 & Reaction to last-minute crises & Creditors & & 3 \\
\hline Omissions and mistakes & 0.15 & Allegations, blamed for & Creditors & Reports & 3 \\
\hline \multicolumn{6}{|c|}{ Evaluation criterion 5 - BRP competencies and performance } \\
\hline Impartiality & 0.25 & $\begin{array}{l}\text { Feedback from stakeholders, } \\
\text { independence of decision-making }\end{array}$ & Stakeholders & $\begin{array}{l}\text { Formal complaints to CIPC, } \\
\text { audit reports }\end{array}$ & 3 \\
\hline Sensemaking & 0.2 & Story as told & BRP & Evidence and metrics & 4 \\
\hline Ethics and governance & 0.1 & Allegations, behaviour & $\begin{array}{l}\text { Stakeholders, creditors, } \\
\text { employees }\end{array}$ & $\begin{array}{l}\text { Section } 75,76,77 \text { and tax } \\
\text { clearance, SARS file }\end{array}$ & 3 \\
\hline $\begin{array}{l}\text { Skills set match to turnaround } \\
\text { situation (TAS) }\end{array}$ & 0.15 & Comparative judgement & Audit judgements, BRP & & 4 \\
\hline Collaboration and communication & 0.15 & Feedback, employee, board & Stakeholders & $\begin{array}{l}\text { Feedback, employee, board, } \\
\text { conflict resolution }\end{array}$ & 3 \\
\hline Advisors' knowledge and team & 0.15 & Composition & Act & $\begin{array}{l}\text { Appointments and removals, } \\
\text { knowledge feedback }\end{array}$ & 4.5 \\
\hline Integration and implementation & 0 & $360^{\circ}$ feedback & & & 1 \\
\hline \multicolumn{6}{|l|}{ Evaluation criterion 6 - Rescue plan } \\
\hline Basic variables included & 0.25 & & Rescue plan & Checklist from Section 150 & 4 \\
\hline Investigated comparisons & 0.15 & Description of causes and issues & Rescue plan & Values & 1 \\
\hline $\begin{array}{l}\text { Post-commencement finance } \\
\text { decision-making ability }\end{array}$ & 0.1 & $\begin{array}{l}\text { Decision-making tools } \\
\text { (cash flow) }\end{array}$ & Rescue plan & Accessed, affected & 4 \\
\hline Point of arrival description & 0.1 & Clearly described & Rescue plan & Inclusion & 4 \\
\hline Appropriate strategy selection & 0.2 & Matching TAS and strategy & Act & $\begin{array}{l}\text { Long-term debt restructuring } \\
\text { principle }\end{array}$ & 4 \\
\hline
\end{tabular}


TABLE 3 (Continues...): Evaluation criteria and variables in the proposed evaluation framework for business rescue events.

\begin{tabular}{|c|c|c|c|c|c|}
\hline Variable & Weight $\uparrow$ & Interview judgements & Potential sources & Potential evidence (Metrics) & Rating: \\
\hline Acceptance of plan & 0.15 & Voting and acceptance, practical & Minutes & $\begin{array}{l}\text { Minutes, objections, voting, } \\
\text { filing, termination records }\end{array}$ & 4 \\
\hline Executability of plan & 0.05 & Judgement, definiteness & Rescue plan & & 4 \\
\hline \multicolumn{6}{|c|}{ Evaluation criterion 7 - Supreme task (Protocol compliance) } \\
\hline Compliance with Act & 0.25 & & Lawyers & $\begin{array}{l}\text { Repercussions, court, objections, } \\
\text { omissions }\end{array}$ & 4 \\
\hline Keeping to timelines & 0.2 & & Rescue plan & $\begin{array}{l}\text { Extensions, adherence, re-file, } \\
\text { ex parte }\end{array}$ & 4 \\
\hline Creditors' claims system & 0.1 & & Rescue plan & Register, percentage confirmed & 3 \\
\hline Board disclosure documents & 0.1 & & Rescue plan & $\begin{array}{l}\text { Director declarations, auditor } \\
\text { reports }\end{array}$ & 4 \\
\hline Record-keeping and minutes & 0.15 & & Rescue plan & $\begin{array}{l}\text { Register, minute book, } \\
\text { resolutions, BRP payments }\end{array}$ & 4 \\
\hline Section 132(3) compliance & 0.15 & & Regulator enquiry & $\begin{array}{l}\text { Notification after } 3 \text { months of } \\
\text { affected persons and CIPC, court }\end{array}$ & 4 \\
\hline Completions with CIPC & 0.05 & & Regulator enquiry & CoR notices, reports & 4 \\
\hline
\end{tabular}

$\dagger$, Weights are allocated based on the relevance for the specific rescue under investigation. Some variables are more influential depending on the specific context; $\downarrow$, Rating based on a Likert scale where post-mortem performance on variables are rated $1=$ Extremely poor and $5=$ Extremely well.

BRiL, better return than in immediate liquidation; BRP, business rescue practitioner; CIPC, Companies and Intellectual Property Commission; TAS, turnaround situation.

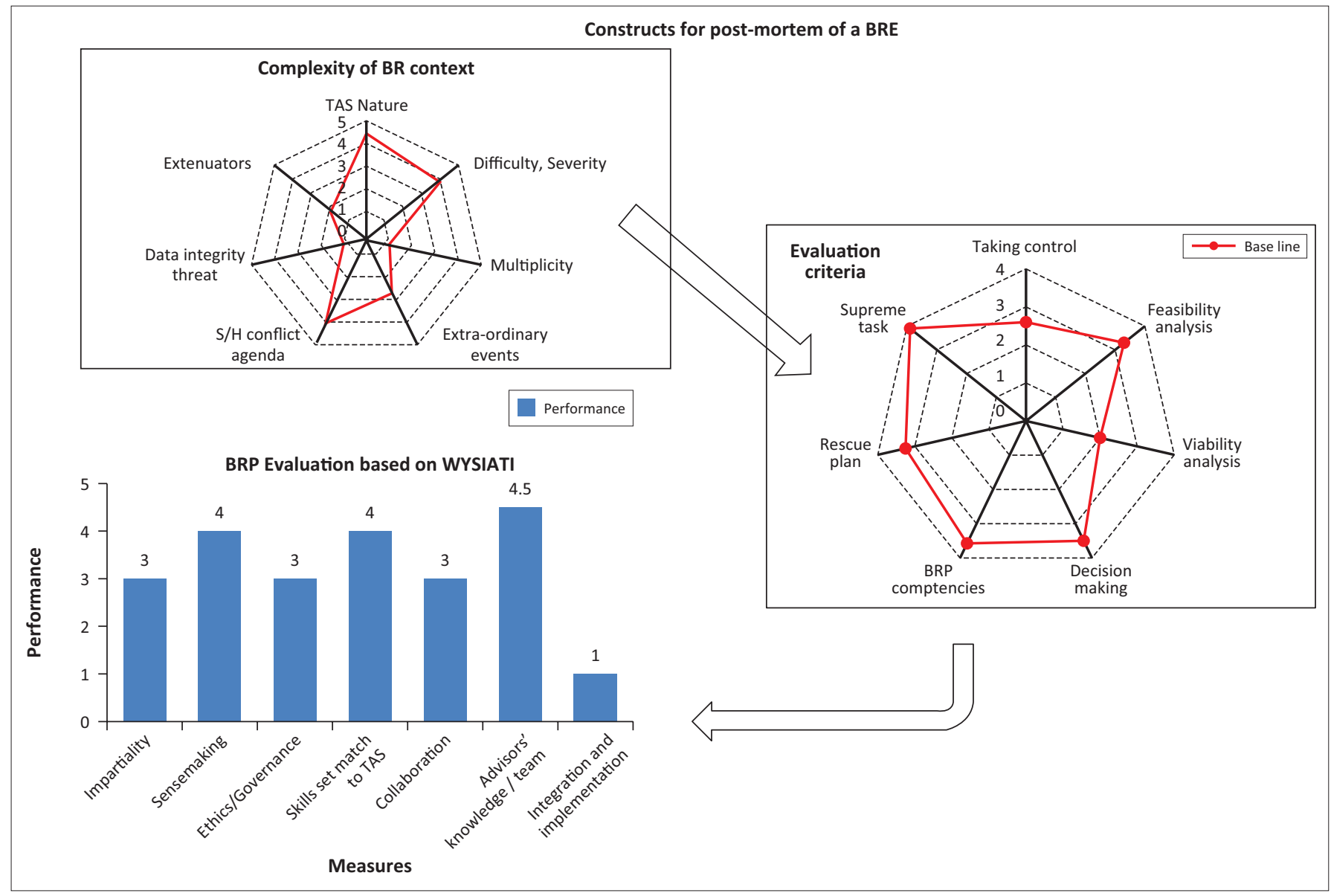

$B R$, business rescue; BRP, business rescue practitioner; TAS, turnaround situation; WYSIATI, what you see is all there is.

FIGURE 1: Outcome example for the post-mortem analysis of a business rescue event.

prescribed within Section 140 of the Act, as well as reported by Pretorius (2013) for BRP tasks. Taking control is when the BRP becomes the main decision-maker (whether autocratic or democratic) in the rescue. One subject suggested that 'it's maybe less important to take control - it's more about taking control away from existing management as they created the problem'.
This management control incorporates the following variables: (1) managerial (including the board) control, (2) financial control and (3) employee control and support with (4) clarification of roles of all affected parties, especially existing management. Management control also depends on (5) communication and meeting with affected parties while sharing the (6) implementation steps and, finally, (7) control 
of the change management process. It is obvious that these are all associated with the BRP tasks and responsibilities.

\section{Evaluation criterion $\mathbf{2}$ - Feasibility analysis}

Feasibility as a concept is typically associated with start-up projects and business but also acknowledged as a test in bankruptcy proceeding (Baldiga 1996). Feasibility basically investigates whether the ingredients exist for a project to be successful and what King (1975:303) refers to as 'workable' where workable suggests that the value of these components (ingredients) combined meaningfully is more than the sum of the individual production factors (assets) in liquidation. This is a prerequisite for the first creditors' meeting and better known as the existence of 'reasonable prospect' as described in Section 129(1)b of the Act. Gottfredson, Schaubert and Hirzel (2008:29) further equate this feasibility analysis to 'determining the point of arrival' compared to a viability analysis as 'determining the point of departure' in the turnaround process.

The variables required for a feasible business model should therefore exist if these are combined appropriately when a profitable future venture could ensue. Typically these variables should include (1) feasibility of demand, capacity (resources, process and assets) to generate an economic or business (profitable) model and the ability for cash generation. Feasibility depends largely on the (2) identification of the turnaround situation which requires clarity on the (3) causality of the current distress (Sections 129(1)b and 152(1) b). It appears that the (4) operating mindset (BRP's belief around existence of current operations and maintaining it) and feasibility are important requirements. How the BRP responded to the (5) contextual difficulty (matching turnaround strategy to the problem) is critical and a (6) basic analysis (Section 150[c]) of the BRE at this point is required. Finally, cognisance of any (7) caveats (fatal flaws or constraints) determines how well the feasibility was calculated. Practitioners must judge whether they have a business to save (corpse vs potential life metaphor).

Frequently, feasibility judgement depends on perceptions, insights, experience and the intuition of the practitioner, founded on the initial information as gathered before the first creditors' meeting. One subject explained it as follows: 'at the first creditors' meeting, the emotions and blame fly high - all they want to know is if there is a prospect of getting their money back'. The BRPs report this to creditors if they believe there is a reasonable prospect of creating a rescue plan to do so. Often, at this early stage, feasibility judgements suffer from the liability of data integrity phenomenon (Pretorius \& Holtzhauzen 2008) and asymmetry of information (Pretorius 2016), which is the motive behind the viability analysis where verification is done. Once feasibility is determined and agreed upon by the creditors, the BRP proceeds to the next indicator, namely viability analysis (due diligence).

\section{Evaluation criterion $\mathbf{3}$ - Viability analysis}

Viability analysis (often synonymous with due diligence) typically seeks an intensive review and verification of all aspects of the BRE and its context to (1) overcome the data integrity liability. Comparisons are made with (2) liquidation benchmarks (Section 150[2]aiii of the Act) followed by proper verifications of (3) cash status, the (4) balance sheet status (solvency), (5) a pre-filing investigation of the firm's management and finance, (6) the bank's role and involvement with management. The execution of (7) forensic reports and the requirement to do so completes the viability analysis and satisfies this part of the post-mortem.

Most relevant to the viability question is that the information needed to answer it must be incorporated into the rescue plan to be presented at the second creditors' meeting to assist decision-making for voting (Section 150[2]). Midanek (2002:23) linked it to a 'glass assessment' - transparency for creditors and affected parties. This is supported by Kieurlff and Peterson (2009:45), who advanced that understanding of the financials, cash flow and verification of data (data integrity) are key turnaround management practices. Viability analysis follows feasibility closely through verification of assumptions made during feasibility analysis under the task of 'investigating the affairs' (Section 141).

\section{Evaluation criterion 4 - Business decision-making}

Decision-making is what BREs depend on as shown by King's quotation in the introduction. To evaluate BRE decision-making, there are key variables to consider, including (1) the decision to pursue BR in the first place, which may be influenced by type I and type II errors to pursue likely and unlikely rescues as described by Argenti (1976). Decisions to control (2) retrenchment of staff (always likely in retrenchment actions) need evaluation (Schmitt \& Raisch 2013:1218). Decision-making in the (3) daily operations is followed by the (4) choice (motive) for pursuing reorganisation versus $\mathrm{BRiL}$ as options. Decisions taken regarding the (5) protection of demand, (6) responding to the so-called ' 5 to 12 issues' (last-moment crises) that may have appeared and, finally, (7) blatant omissions and mistakes made during the BRE complete the evaluation of decisions during the process. Again the decision-making depends largely on the competencies of the BRP as the core decision-maker.

\section{Evaluation criterion 5 - Business rescue practitioner competencies and skills}

Much has been written and reported about the competencies of BRPs (McCann 2009). It remains 'the' bone of contention where BRPs are still widely criticised for incompetence. A banker confirmed several subjects who referred to 'rogue BRPs in the industry'. Therefore, the need that this study addresses includes the competency evaluation of the BRP and the proposed alteration of the accreditation and appointment process. Pretorius (2014) has previously elaborated on the specific competencies for BRPs. This study however proposes adding: (1) BRP impartiality to the (2) sensemaking competency; how (3) ethical the governance pursued by the BRP and the (4) skills match to the turnaround 
situation influence how the competencies are perceived (industry knowledge and experience). Finally, a judgement on the (5) collaboration during the BRE, the (6) use of advisors (legal, financial, forensic specialists) and how well (7) integration was achieved during implementation of the plan covers the key associated competencies.

\section{Evaluation criterion $\mathbf{6}$ - The rescue plan}

Preparing the rescue plan is a key task (Sections 128[b]i and 150), which subjects suggested to be the 'unique task' of the BRP and their main duty (Loubser 2010a:105). In this research it appeared that the compilation of the rescue plan is a central variable of 'everything rescue'. As one subject suggested, 'show me the plan and I will show the competence of the $\mathrm{BRP}^{\prime}$. Evaluating the rescue plan requires judging whether the (1) basic variables were included (Section 150), (2) all alternatives were investigated and the (3) 'point of arrival' is sufficiently described for meaningful (4) PCF decisionmaking (Du Preez 2012; Pretorius \& Du Preez 2013). Next and crucially, the plan is judged for the (5) appropriate strategy (in response to the context, TAS and causality). Here, subjects pointed to certain BRPs who operate purely by debt restructuring over longer terms (in all their rescues) while they never fix the problems sustainably within the BRE - a significant allegation. Finally, it is important to know whether the (6) plan was voted for and, lastly, its (7) executability (it cannot be 'pie in the sky', as suggested by one subject).

The rescue plan is also the main source of information for the PMA (see Table 2 and Table 3 ) and should be sufficient for a large portion of the data barring the opinions of affected parties for confirmation and verification.

\section{Evaluation criterion 7 - Following protocols}

Staying within the Act is very important, as stated by a subject: 'no matter what, move within the legal process - there is sufficient case law'. Following protocols directly alludes to (1) compliance with the Act (Section 129) as far as (2) timelines, (3) compilation of a creditor claim system, obtaining (4) board disclosure statements and proper (5) record keeping (time sheets and costs). Finally, (6) adherence to Section 132(3) requirements of notifications and consideration of (7) CIPC document submissions are useful for judging this indicator.

Several of the variables contained in the various evaluation criteria appeared to be associated with other evaluation criteria, as well as being interrelated (not statistically determined). The researcher judged the appropriate allocation based on his view of the most relevant category.

\section{Discussion of findings, key theoretical components and insights from the study}

To enhance meaningful coverage of the findings, this section deliberates on important aspects of the findings as they may influence the evaluation, as well as direct theory formation.
The findings are then elaborated on and explored for improved understanding of the proposed framework for post-mortem analysis of a BRE.

\section{Variable weights and contribution}

Several variables are contained within each indicator but with different relevance and importance depending on the specificity of the BRE. It is known that while there are generic principles across BREs, every event has unique features and variable manifestations as already alluded to.

In this proposed framework, the above is addressed by the allocation of weights (total $=100 \%$ per indicator) to the variables based on their relevance within the specific BRE. For example, when evaluating context complexity, multiplicity may be irrelevant for many smaller rescues and therefore can be weighted at zero contribution so as not to force a judgement. Other variables are then weighed at higher values. The benefit of this weighting lies in the flexibility it provides to the 'evaluators'.

\section{Data and information sources}

The liability of data integrity has been identified as a key to the meaningful analysis of a BRE. The proposed framework suggests the application of various sources to verify information. The sources of information identified by the subjects are shown in both Table 2 and Table 3 but are not limited to those. Experienced investigators can enhance these with additional tools and techniques. When testing the process in two different cases, it appeared that the BRP and rescue plan are the primary sources of information. Unfortunately the BRP is also an indicator which made the information supplied subject to 'self-serving bias'. Therefore secondary and tertiary sources need to be incorporated for verification. A key source is the creditors' committee which must involve the bank. This, however, will depend largely on the specific variable under discussion.

Interviews with various parties are suggested as sources of information. These are known to be time-consuming but the verification through data source triangulation is a known benefit especially where it is expected that biased responses especially from the BRP - are a natural occurrence. The evaluators will start with the plan, clarify through the BRP interview and then confirm through interviews with the bank, creditors, employees, shareholders, other affected parties and even outsiders who may be industry experts.

The rescue plan as a source of information appears crucial and presentation of a comprehensive and proper plan means there is less demand for extensive interviews to verify the evidence presented. Table 3 shows that the rescue plan should be the source of almost $50 \%$ of all the variables, hence the crucial value of the plan in the overall post-mortem analysis. This researcher has studied many plans and the word 'appalling' comes to mind in many cases. Unfortunately there is little pressure (and none by the Act or regulator) for 
submission of plans as part of compliance. Several reasons for this status can be proposed.

\section{Evidence}

To make decisions and obtain knowledge that guides one's beliefs about the evaluation criteria call for evidence from the sources of information. While different evaluators may use different evidence, Table 2 and Table 3 also provide for potential metrics to use as evidence. The value of the proposed metrics to use is twofold: firstly, not to submit to personal bias and, secondly, to attempt some form of standardisation that will support credibility. Again, for different BREs metrics may or may not exist, for example attempted removals of BRPs by affected persons are not relevant in all cases thus removals, if they exist, will carry high weightings.

Kahneman (2011) suggests that decision-making often hinges on the concept of 'what you see is all there is', which requires a judgement based on less than all the information. It is more important to make the judgement and potentially improve it rather than make no judgement at all.

\section{Variable rating}

Finally, the proposed framework allows for rating each relevant variable after it has been weighed based on its contribution. Generally a 5-point scale is proposed. The context variables are rated based on their contribution to difficulty (as per the perception of the evaluator, with $1=$ very easy and $5=$ very difficult). The indicator ratings are also on a 5-point scale based on an agreement scale ( $1=$ totally disagree and $5=$ totally agree). Typically, an overall rating of below 2 will be regarded as poor while 4 and above is regarded as good performance. The neutral value of 3 is used for unknown information as it does not 'skew' the overall indicator performance. Very important is the direction of the rating such that a negative evaluation (absence of difficulty) has a low rating because the interest of the indicator is the complexity of the BRE.

\section{Additional observations}

While seven evaluation criteria are proposed to determine the success of a BRE retrospectively, the research shows that the $\mathrm{BRP}$ and his role, tasks directed by the Act, influence and powers act as a disproportionate influencer during the rescue. The BRP is the inherent centre of the process (Jacobs 2012). As all the evaluation criteria relate to the BRP, they are proposed as the mediating factor in the rescue process. The link to appointment, training and accreditation is therefore expounded exponentially. This accreditation requirement led to the proposed framework to report the variable elements of the BRP competencies indicator as a separate category. The final outcome of the framework is shown in Figure 1 to contain three diagram constructs, namely the contextual difficulty, the BRP evaluation and the overall BRE performance.

Who does the evaluation is also crucial to the meaningful use of such a framework. It appears that evaluator competence should be that of expert or master level competencies and not novices, proficient or even competent as described by Dreyfus and Dreyfus (1980). This suggests that such a process may become very costly. Therefore, the suggestion of using peer-review processes as used by the Engineering Council of South Africa (ECSA 2016) when evaluating failed projects.

\section{Answering the research question: What are potential evaluation criteria for post-mortem analysis of a business rescue event?}

The compilation of the framework has clearly confirmed the complicated environment in which the BRP must operate. Seven evaluation criteria with 49 interrelated and overlapping variables have been identified by the research for consideration during the PM process. This seems to be in line with Collett, Pandit and Saarikko (2014:123) who identified 23 generic decline and recovery variables in a literature review. A visual depiction of the evaluation criteria is shown in Figure 1. During practical application of the proposed framework, evaluators must take cognisance of the context factors and the mediator role of the BRP in the process. For that reason, both context and the BRP competencies are expanded to show deeper analysis, which addressed the usefulness for application in accreditation and new applications to become BRPs.

From Figure 1 it is clear that the outcome of the proposed framework application points to three important constructs as a result of the PMA. Firstly, the BRE context and strategic BR complexity of the BRE that informs about the difficulty of the specific rescue. 'All rescues are not the same' was voiced by most subjects. Secondly, the evaluation criteria are shown and may suggest where problems may have occurred - these can then be further investigated. Thirdly, the BRP evaluation that can be directly related to the accreditation for future appointments needs consideration. Pretorius (2014) proposed that navigating the business in rescue towards the new 'best' position is the ultimate assignment of BRPs. To evaluate this navigation by the BRP, the evaluation criteria can direct the judgement. Evaluation criteria cannot be addressed in isolation but should be used in 'concert', as proposed by Schoemaker, Krupp and Howland (2013:2). The interdependence of the variables, within and between evaluation criteria requires that every business rescue evaluation requires master competence level insight and experience to be meaningful. Evaluators require a keen sense of context. Finally, Figure 1 confirms the vast number of issues when executing the BRE PMA. Add to it the evaluation situatedness (who makes the judgement) and it sanctions the complexity of the proposed procedures.

\section{Conclusions and industry implications}

This study set out to extend the tasks and activities (input perspective) of BRPs during business rescue as reported by Pretorius (2013). His findings (Pretorius 2014) are 
competencies described requirements (process perspective) while this study approaches BR from an output perspective. It extends the directives of Conradie and Lamprechts (2015) about measurement of BR success.

It is proposed that the framework be used to elicit conversation about a sensitive and difficult but necessary topic in the BR industry. The framework is a first step and calls for vigorous debate and critique on its assumptions, processes, application, usability and value. The framework's main value is found in the flexibility of using the weightings of variables as these variable weightings respond to the unique contextual situatedness of the distressed venture on entering the rescue process.

Finally, the evaluation criteria gave direction to the tasks, competencies and success criteria proposed by previous research. Navigating the rescue is the task assigned to the BRP at the start of the process. To measure successful navigation appears to be more complex than just measuring outcome. These evaluation criteria and their manifestation within a context express additional direction towards how education for BRPs could be enhanced, as well as point towards the potential prerequisites of BRP accreditation in future.

\section{Implications for the rescue industry}

Several contributions and improved insights for theory application were observed when compiling the proposed framework.

Firstly, the overlapping nature of variables within and across the evaluation criteria is highlighted. In particular complex rescues: multiple units and corporate structures may affect the complexity of the BRE and require judgements of the variables at expert levels. The related competencies and level of the BRP are then screened much more intensely. The BRP therefore is disproportionately judged because of their tasks and decisions during the rescue. The question arises whether such variables should be deemed relevant as training content for BRPs, or should they be assumed to be part of the makeup of future application processes? Selection and accreditation of a BRP is probably the most important decision for boards, directors and the courts. It may be useful to look towards the professional bodies to provide accredited members to prospective filing directors. Professional bodies can use the framework to accumulate data based on the outcomes of such evaluations.

Secondly, reflecting on the proposed framework confirmed that the rescue plan is a key source of evidence and its preparation appears to be the unique and main contribution of the rescue practitioners. The rescue plan is the central document (Loubser 2010b) but the requirements in Section 150 of the Act for the plan appear insufficient for proper decision-making. It is known that some practitioners 'copy and paste' from other plans without removal of the specific information and names from the plan they copy. While there is research on rescue plans (Pretorius \& Rosslyn-Smith 2014; Rosslyn-Smith \& Pretorius 2015) there remains a lack in this area as to the variables of a good rescue plan. Often the success of a rescue is as good as the implementation of the plan. It is proposed that the rescue plan moves up the ladder of importance for future research.

Thirdly, the proposed framework highlighted the intersection of the BRP and the BR and their inseparability. As a matter of fact, the framework turned out to be one that evaluates the decisions made by the BRP in its entirety barring the contextual evaluation. While the aim was to evaluate the rescue, it turned out to be a test of the BRP as much as of the rescue. It can be stated that the BRP is totally embedded in the rescue where embedded refers to the instilling of practices (behaviours, actions, beliefs and attitudes) about something (decision-making) into the surrounding mass (BRE) to become an integral part of all aspects of the rescue.

Fourthly, while it was unintended, the evaluation framework turned out to be useful as a competency framework for BRPs, making its contribution to guide professional bodies in accreditation processes even more significant. To address the problem of 'who evaluates' the BRE, it is proposed that a small-team investigation be done to create conversation about the status, weights, ratings and credibility of the sources used, which are specifically relevant to the BRE under investigation.

Fifthly, education institutions could apply the findings by incorporating the evaluation criteria as topics into BRP training courses. The regulator, for example, as the governing body controlling BR could now use the proposed framework to investigate complaints received. The framework should be investigated through further research and be established as the continuous measurement in BRP accreditation after formal training.

Finally, competence measurement was addressed in this article. The key question that arises is where expert and master BRPs are going to be found for evaluation purposes. While peer evaluation was proposed, there are few BRPs who can operate at this level.

\section{Limitations and future research}

Despite the data being directly obtained from the subjects, the main limitation of this research is potential researcher bias during both the data analysis and interpretation of results phases. Secondly, the dependence of the framework on human judgement and its associated subjectivity remain a huge barrier and therefore a challenge for future research.

One could rightly ask why the framework is balanced with seven variables per criterion and if the subjects identified them as such. The answer is 'no' as the framework is the conceptualisation of the researcher that should now be scrutinised by further research. 
The relevance (weighting) of each variable remains subject to the interpretation of the evaluator considering the specific context for each BRE.

It is uncertain if the application of this proposed BRE PMA outcome would serve as sufficient evidence in a court. Probably, the evaluators will be subjected to more scrutiny than the BRE itself.

Future research should therefore seek validation and refinement of the evaluation framework and expansion to a formal accreditation model. Evaluator criteria and rating also require future research.

Preparing the rescue plan should become a research focus and formal guidelines should be developed by educators.

\section{Acknowledgements Competing interests}

The author declares that he has no financial or personal relationships which may have inappropriately influenced him in writing this article.

\section{References}

Argenti, J., 1976, 'Corporate planning and corporate collapse', Long Range Planning 9(6) 12-17. https://doi.org/10.1016/0024-6301(76)90006-6

Baldiga, N.R., 1996, 'Is this plan feasible? An empirical legal analysis of plan feasibility', Commercial Law Journal 101(2), 115-132.

Baird, S. \& Lorence, M., 2012, 'Predicting success: A doctoral research study', Journal of Corporate Renewal Nov/Dec, 20-23.

Bjornson, F.O., Wang, A.I. \& Arisholm, E., 2008, 'Improving the effectiveness of roo cause analysis in post-mortem analysis: A controlled experiment', Information and Software Technology 50(5), 832-867.

Bradstreet, R., 2010, 'The leak in the Chapter 6 lifeboat: Inadequate regulation of business rescue practitioners may adversely affect lenders: Willingness and the growth of the economy', South African Mercantile Law Journal 195-213, viewed growth of the economy', South African Mercantile Law Jour
18 November 2012, from http://www.companylaw.uct.ac.za

BRPortal, 2013, Second-generation scenarios for business rescue in South Africa, viewed 16 April 2015, from http://www.brportal.co.za/forum

Collet, N., Pandit, N.R. \& Saarikko, J., 2014, 'Success and failure in turnaround attempts. An analysis of SMEs within the Finnish restructuring of enterprise act', Entrepreneurship and Regional Development 26(1-2), 123-141. https://doi.org/ 10.1080/08985626.2013.870236

Collier, B., DeMarco, T. \& Feary, P., 1996, 'A defined process for project post-mortem review', IEEE Software 13(4), 65-72. https://doi.org/10.1109/52.526833

Conradie, S. \& Lamprecht, C., 2015, 'Business rescue: How can its success be evaluated at company level?', Southern African Business Review 19(3), 1-29.

Corbin, J. \& Strauss, A., 1990, 'Grounded theory research: Procedures, canons and evaluative criteria', Qualitative Sociology 13(1), 3-21. https://doi.org/10.1007/ BF00988593

Davies, R., 2016, Internal letter from the Minister of Trade and Industry to the Regulator.

Dreyfus, S.E. \& Dreyfus, H.L., 1980, A five-stage model of mental activities involved in directed skills acquisition, Operations Research Center, University of California, Berkeley, CA.

Du Preez, W., 2012, 'The status of post commencement finance for business rescue in South Africa', unpublished BBA thesis, GIBS, University of Pretoria.

ECSA, 2016, Engineering Council of South Africa, viewed 12 February 2016, from http://www.ecsa.co.za/documents/AbbreviationsProfessionalTitles.pdf

Elliot, A., 2015, 'Business Rescue success - who wants to know?', presentation at the Annual Gibs Conference on BR, September, 6(9), 3-13.
Edvardsson, B. \& Roos, I., 2001, 'Critical incident techniques: Towards a framework for analysing the criticality of critical incidents', International Journal of Service Industry Management 12(3), 251-268. https://doi.org/10.1108/EUM0000000005520

Fischhoff, B., 1980, For those condemned to study the past: Reflections on historical judgement, DARPA Technical Report: PTR-1091-80-5, May, Defense Advanced Projects Agency, Arlington County, VA.

Gottfredson, M., Schaubert, S. \& Hirzel, A., 2008, 'Leading fast turnarounds', Business Strategy Review Autumn, 28-33. https://doi.org/10.1111/j.1467-8616. 2008.00549.x

Henning, E., 2011, Finding your way in qualitative research, Van Schaik, Pretoria.

Jacobs, L.M., 2012, 'Die nuwe ondernemingsreddingpraktisyn: Geneesheer of begrafnisondernemer? 'n Ondersoek na die kwalifikasies van die reddingspraktisyn', Litnet Academic 9(2), viewed 10 September 2012, from http:// www.litnet.co.za

Kahneman, D., 2011, Thinking, fast and slow, Penguin, London.

Kierulff, H. \& Peterson, H.L., 2009, 'Finance is everything: Advice from turnaround managers', Journal of Business Strategy 30(6), 44-51. https://doi.org/ 10.1108/02756660911003112

King, D.R., 1975, 'Feasibility in chapter X reorganizations', Villanova Law Review 20, 302-372.

Kurtz, C.F. \& Snowden, D.J., 2003, 'The new dynamics of strategy: Sensemaking in a complex and complicated world', IBM System Journal 42(3), 462-483. https://doi. org/10.1147/sj.423.0462

Loubser, A., 2010a,' The business rescue proceedings in the Companies Act of 2008 Concerns and questions (part 1)', Tydskrif vir Suid Afrikaanse Reg 3, 501-514.

Loubser, A, 2010b, 'The business rescue proceedings in the Companies Act of 2008 : Concerns and questions (part 2)', Tydskrif vir Suid Afrikaanse Reg 3, 689-701.

McCann, P., 2009, Turnarounds: Brains, guts and stamina, Trafford Publishing, Bloomington, IN.

Midanek, D.H., 2002, 'How to pick the right turnaround manager', Journal of Private Equity Fall, 21-24. https://doi.org/10.3905/jpe.2002.320019

Myllyaho, M., Salo, O., Kääriänen, J., Hyysalo, J. \& Koskela, J., 2004, 'A review of small and large post-mortem analysis methods', Proceedings of the ICSSEA 2004, Paris, 30 November-02 December.

Pretorius, M., 2008, 'When Porter's generic strategies are not enough: Complementary strategies for turnaround situations', Journal of Business Strategy 29(6), 19-28. https://doi.org/10.1108/02756660810917200

Pretorius, M., 2013, 'Tasks and activities of the business rescue practitioner: A strategy as practice approach', South African Business Review 17(3), 1-26, available from http://www.unisa.ac.za/contents/faculties/service_dept/docs/Sabview_17_3 Chap\%201.pdf

Pretorius, M., 2014, 'A competency framework for the business rescue practitioner profession', Acta Commerci 14(2), 1-15. http://www.actacommercii.co.za/index. php/acta/article/viewFile/227/325

Pretorius, M., 2015, Business rescue status report, unpublished report presented to the Regulator.

Pretorius, M., 2016, 'The debtor friendly fallacy in business rescue: Agency theory moderation and quasi relationships', Southern African Journal of Economics and Management Sciences 19(4), 479-496.

Pretorius, M. \& Du Preez, W., 2013, 'Constraints on decision making regarding post commencement finance in business rescue', South African Journal of Entrepreneurship and Small Business Management 6, 168-191. https://doi. org/10.4102/sajesbm.v6i1.39

Pretorius, M. \& Holtzhauzen, G.T.D., 2008, 'Critical variables of venture turnarounds: A liabilities approach', Southern African Business Review 12(2), 87-107.

Pretorius, M. \& Holtzhauzen, G.T.D., 2013, 'Business rescue decision making through verifier determinants: Ask the specialists', South African Journal of Management Sciences 16(4), 468-485, viewed n.d. from http://sajems.org/index.php/sajems/ issue/view/37

Pretorius, M. \& Rosslyn-Smith, W., 2014, 'International guidelines for business rescue plans', South African Business Review 18(2), 108-139.

Rosslyn-Smith, W.R. \& Pretorius, M., 2015, 'International guidelines for business rescue plans', Southern African Journal of Entrepreneurship and Small Business 7 , 1-35. https://doi.org/10.4102/sajesbm.v7i1.4

Schmitt, A. \& Raisch, S., 2013, 'Corporate turnarounds: The duality of retrenchment and recovery', Journal of Management Studies 50(7), 1216-1244. https://doi. org/10.1111/joms.12045

Schoemaker, P.J.H., Krupp, S. \& Howland, S., 2013, 'Strategic leadership: The essential skills', Harvard Business Review January-February, 131-134.

Trahms, C.A., Ndofor, H.A. \& Sirmon, D.G., 2013, 'Organizational decline and turnaround: A review and agenda for future research', Journal of Management 39, 1227-1307. https://doi.org/10.1177/0149206312471390

Yin, R.K., 2003, Case study research: Design and methods: Applied social research methods series, 2 nd edn., 5, Sage, London. 